\title{
TGF- $\beta 1$-induced autophagy activates hepatic stellate cells via the ERK and JNK signaling pathways
}

\author{
JING ZHANG ${ }^{1,2^{*}}$, NA JIANG ${ }^{1,2^{*}}$, JIAN PING $^{1-4}$ and LIEMING XU ${ }^{1-4}$ \\ ${ }^{1}$ Shuguang Hospital Affiliated to Shanghai University of Traditional Chinese Medicine; ${ }^{2}$ Institute of Liver Diseases, \\ Shanghai University of Traditional Chinese Medicine; ${ }^{3}$ Shanghai Key Laboratory of Traditional Chinese Medicine; \\ ${ }^{4}$ Key Laboratory of Liver and Kidney Diseases, Ministry of Education, Shanghai 201203, P.R. China
}

Received February 7, 2020; Accepted September 29, 2020

DOI: $10.3892 / \mathrm{ijmm} .2020 .4778$

\begin{abstract}
Transforming growth factor $\beta 1$ (TGF- $\beta 1$ ) is one of the most important fibrogenic factors promoting the activation of hepatic stellate cells (HSCs). Autophagy is a process used by cells to degrade and recycle cellular proteins. Although TGF- $\beta 1$ induces autophagy in several other cellular systems, the association between its effect on fibrogenesis and autophagy in HSCs have not been determined. Liver tissues from C57BL/6 mice and the mouse HSC line JS1 were analyzed. Acute and chronic liver injury models were induced by carbon tetrachloride $\left(\mathrm{CCl}_{4}\right)$, and JS1 cells were stimulated by TGF- $\beta 1$ to assess the mechanism and relationship between autophagy and fibrosis. Liver tissues from acute and chronic injury models induced by $\mathrm{CCl}_{4}$ demonstrated evidence of increased autophagic activity, as assessed by the expression of the microtubule-associated protein 1 light chain 3BII protein. TGF- $\beta 1$ stimulated the activation of JS1 cells and simultaneously increased autophagy flux. However, this effect was attenuated when autophagy was inhibited using chloroquine, 3-methyladenine or lentiviral short hairpin RNA-mediated knockdown of autophagy-related gene 7. Furthermore, whether MAPK, including ERK, JNK and p38 MAPK cascades were associated with TGF- $\beta 1$-induced autophagy in JS1 cells was determined. Subsequently, it was shown that the ERK inhibitor, PD98059, and JNK inhibitor, SP600125, were able to reverse TGF- $\beta 1$-induced autophagy and fibrosis. The results of the present study suggest that TGF- $\beta 1$-induced autophagy is involved in the activation of JS1 cells, possibly through activation of the ERK and JNK signaling pathways.
\end{abstract}

Correspondence to: Dr Lieming Xu, Shuguang Hospital Affiliated to Shanghai University of Traditional Chinese Medicine, 528 Zhangheng Road, Pudong New Area, Shanghai 201203, P.R. China

E-mail: xulieming@shutcm.edu.cn

${ }^{*}$ Contributed equally

Key words: autophagy, transforming growth factor $\beta 1$, hepatic stellate cells, mitogen-activated protein kinase, liver fibrosis, apoptosis

\section{Introduction}

Hepatic fibrosis is a wound-healing response that requires a range of cell types and mediators to encapsulate the injury (1). Activation of resident hepatic stellate cells (HSCs), the primary source of extracellular matrix (ECM) proteins, into proliferative, contractile and fibrogenic cells serves a pivotal role in fibrosis (2). Among the numerous fibrogenic factors involved in the activation of HSCs, one of the most important is transforming growth factor $\beta 1$ (TGF- $\beta 1$ ), which can affect HSC growth and differentiation, as well as the production of ECM proteins (3). The discovery of HSC activation induced by TGF- $\beta 1$ remains meaningful in understanding the basis of hepatic fibrogenesis.

Autophagy is an essential catabolic degradation process, in which cellular proteins, organelles and invading microbes are engulfed by double-membraned autophagosomes and are degraded in the lysosomes (4). Autophagy serves dual roles dependent on the conditions, promoting survival or promoting cell death (4). Recently, autophagy has been implicated in a variety of liver diseases $(5,6)$. The selective breakdown of lipids stored in lipid droplets by autophagy is termed lipophagy (7). Although originally described in hepatocytes, lipophagy may metabolize lipids in all cells, including HSCs $(7,8)$. Thus, autophagy regulates hepatic metabolism under healthy conditions and various chronic liver diseases, such as fibrosis $(9,10)$. A previous study showed that autophagy flux is increased during activation of HSCs, and autophagy stimulates the loss of lipid droplets (11). This provides cellular energy to promote the survival and activation of HSCs (12). Chloroquine and 3-methyladenine (3-MA), inhibitors of autophagy, may improve carbon tetrachloride $\left(\mathrm{CCl}_{4}\right)$-induced liver fibrosis in vivo $(13,14)$. The mechanism involved in this process includes inhibition of autophagy pathways and inhibition of HSC activation $(13,14)$. However, another study has shown that inducing autophagy promotes the degradation of collagen and reverses hepatic fibrosis (15). The complex function of autophagy in the regulation of fibrosis may differ between various tissues or cells.

Studies have reported that autophagy is involved in regulating the fibrosis of human subconjunctival fibroblasts, tubular epithelial kidney cells, primary human lung fibroblast 
cells, human atrial myofibroblasts and human peritoneal mesothelial cells induced by TGF- $\beta 1$ (16-20). However, the effect of TGF- $\beta 1$ on autophagy in HSC is unclear. In the present study, the relationship and mechanism between autophagy and TGF- $\beta 1$-induced fibrogenesis in JS1 cells, a mouse immortalized HSC line, were assessed.

\section{Materials and methods}

$\mathrm{CCl}_{4}$-induced liver fibrosis. A total of $32 \mathrm{C} 57 \mathrm{BL} / 6$ male mice, aged 6-8 weeks, were purchased from Shanghai Laboratory Animal Resources, Chinese Academy of Sciences (cat. no. SCXK 2007-0005). All mice were housed in specific pathogen-free sterile rooms, with a 12 -h light/dark cycle, at $22 \pm 2{ }^{\circ} \mathrm{C}$ and $40-60 \%$ humidity, with free access to water and food in the Laboratory Animal Center, Shanghai University of Traditional Chinese Medicine. The present study was performed in accordance with the Guide for the Care and Use of Laboratory Animals of the National Institutes of Health. All experimental protocols were approved by Shuguang Hospital Affiliated to Shanghai University of Traditional Chinese Medicine Animal Care and Ethics committee. All mice were randomly divided into control $(n=11)$ and experimental groups $(n=21)$. The experimental group was further subdivided into a chronic injury group $(n=13)$ and an acute hepatic injury group $(\mathrm{n}=8) . \mathrm{CCl}_{4}$ (Sigma-Aldrich; Merck KGaA) was intraperitoneally injected to induce hepatic fibrosis or liver injury. In the chronic injury group, the mice were injected with $12 \% \mathrm{CCl}_{4}$ (diluted in olive oil) three times per week for 6 weeks at a dose of $2 \mathrm{ml} / \mathrm{kg}$ body weight. In the acute hepatic injury group, the mice were injected with a single dose of $0.5 \% \mathrm{CCl}_{4}$ at $5 \mathrm{ml} / \mathrm{kg}$. The control mice were injected with saline at the same dosing schedule as the experimental subgroups. All mice were euthanized by intraperitoneal injection of pentobarbital sodium $(200 \mathrm{mg} / \mathrm{kg})$ after 6 weeks of treatment. Subsequently, liver tissues were removed and immediately cryopreserved in liquid nitrogen for subsequent experiments.

Cells and cell culture. Primary HSCs were isolated from normal and $\mathrm{CCl}_{4}$-induced acute hepatic injured $\mathrm{C} 57 \mathrm{BL} / 6$ mice through enzymatic digestion and $11.5 \%$ Nycodenz density gradient centrifugation with modifications (21). Once adherent, the cells were collected for subsequent experiments. The mouse immortalized HSC cell line, JS1, was kindly provided by Professor Scott L. Friedman (Mt. Sinai School of Medicine, USA). JS1 cells were cultured in DMEM (Gibco; Thermo Fisher Scientific, Inc.) supplemented with 10\% FBS (Gibco; Thermo Fisher Scientific, Inc.) and 1\% penicillin/streptomycin at $5 \% \mathrm{CO}_{2}$ and $37^{\circ} \mathrm{C}$. The medium was changed to media supplemented with $0.5 \%$ FBS for $12 \mathrm{~h}$ prior to treatment. Recombinant human TGF- $\beta 1$ (PeproTech, Inc.) was added to the medium for different durations, according to the design of the experiments. JS1 cells were pre-treated with $10 \mu \mathrm{M}$ PD98059 (cat. no. ab120234; Abcam), $10 \mu \mathrm{M}$ SB203580 (cat. no. ab120162; Abcam) or $10 \mu \mathrm{M}$ SP600125 (cat. no. ab120065; Abcam) for $1 \mathrm{~h}$, followed by treatment with or without $10 \mathrm{ng} / \mathrm{ml}$ TGF- $\beta 1$ for varying durations $(2,4,8$ or $12 \mathrm{~h})$. Each in vitro experiment was repeated three times.

Measurement JS1 cell viability. Cells were plated in 96-well plates and incubated with $0.5,1,5$ or $10 \mathrm{mM} \mathrm{3-MA}$ (cat. no. M9281; Sigma-Aldrich; Merck KGaA), 10, 50 or $100 \mu \mathrm{M}$ chloroquine (CQ) diphosphate salt (cat. no. C6628; Sigma-Aldrich; Merck KGaA) or $100 \mathrm{ng} / \mathrm{ml}$ rapamycin (cat. no. S1842; Beyotime Institute of Biotechnology) with or without TGF- $\beta 1$ (10 ng/ml) for 12 or $24 \mathrm{~h}$. Subsequently, Cell viability was assessed using an MTT Cell Proliferation and Cytotoxicity Assay kit (cat. no. C0009; Beyotime Institute of Biotechnology) according to the manufacturer's protocol. The supernatant was removed after cell treatment, and $90 \mu \mathrm{l}$ fresh culture medium and $10 \mu \mathrm{l}$ MTT solution were added for further culture for $4 \mathrm{~h}$ at $37^{\circ} \mathrm{C}$. The cell supernatant was then discarded, and $100 \mu \mathrm{l}$ formazan was added with gentle shaking for $10 \mathrm{~min}$. The absorbance was recorded at a wavelength of $490 \mathrm{~nm}$ with a microplate reader (SpectraMax M5; Molecular Devices LLC).

Fluorescence staining. Lipid droplets in primary HSCs were stained using $4 \mu \mathrm{M}$ BODIPY 581/591 (cat. no. D3861; Invitrogen; Thermo Fisher Scientific, Inc.) after fixing the cells with $4 \%$ paraformaldehyde for $30 \mathrm{~min}$ at room temperature. Immunofluorescence staining of liver tissue was performed using 7-mm sections sliced using a cryostat machine (CM1850; Leica Microsystems, Inc.) at $-20^{\circ} \mathrm{C}$. The sections were fixed with $100 \%$ acetone for $30 \mathrm{~min}$ at $4^{\circ} \mathrm{C}$ and blocked with 5\% BSA (cat. no. ST025; Beyotime Institute of Biotechnology) for $30 \mathrm{~min}$ at room temperature. Subsequently, two primary antibodies were used for staining: Mouse anti- $\alpha$-smooth muscle actin ( $\alpha$-SMA; $1: 100$; cat. no. AA123; Beyotime Institute of Biotechnology) and rabbit antimicrotubule-associated protein 1 light chain 3B (LC3B; 1:100; cat. no. L7543; Sigma-Aldrich; Merck KGaA) overnight at $4^{\circ} \mathrm{C}$. The sections were subsequently exposed to the following secondary antibodies (Beyotime Institute of Biotechnology): Cy3-labeled goat anti-mouse antibody (cat. no. A0521; 1:100; Beyotime Institute of Biotechnology) or FITC-labeled goat anti-rabbit antibody (cat. no. A0562; 1:100; Beyotime Institute of Biotechnology) for $1 \mathrm{~h}$ at $37^{\circ} \mathrm{C}$. Representative images were captured using confocal microscopy at x100 or x200 magnification (FV10C-PSU; Olympus Corporation). ImageJ 6.0 (National Institutes of Health) was used for quantification of fluorescence intensity and the number of fluorescent cells.

Transmission electron microscopy. Cells were fixed with $2.5 \%$ glutaraldehyde followed by $1 \%$ osmic acid successively for $2 \mathrm{~h}$ at $4^{\circ} \mathrm{C}$. The samples were dehydrated with gradient ethanol and embedded with Epon for $12 \mathrm{~h}$ at $45^{\circ} \mathrm{C}$ and then for $36 \mathrm{~h}$ at $60^{\circ} \mathrm{C}$. Ultra-thin sections were stained with uranyl acetate for $30 \mathrm{~min}$ and lead citrate for $10 \mathrm{~min}$ at room temperature. The ultrastructure was observed using a transmission electron microscope (Tecnai-12 Biotwin; Philips Healthcare).

Lentiviral autophagy-related gene 7 (Atg7) short hairpin RNA (shAtg7) and RFP-GFP-LC3B transduction. shAtg7 expression plasmids were kindly provided by Professor Mark J. Czaja (Albert Einstein College of Medicine, USA). High-titer lentiviral stocks were produced by calcium phosphate-mediated transfection of the modified transfer vectors and the packaging vectors pMDLg-pRRE, pRSV-Rev and pMD2.VSVG into 293T cells (Cell Bank of the Chinese Academy of Sciences). Supernatants were harvested over 36 to $48 \mathrm{~h}$, titered by plaque assay and used at a multiplicity of infection (MOI) of 50 to 
infect JS1 cells. Empty lentiviral vectors were used as the control. JS1 cells were cultured at a density of $1 \times 10^{5}$ cells $/ \mathrm{ml}$ overnight. The medium was then replaced with serum-free medium and JS1 cells were infected with lentiviral shAtg7 or empty vectors with an MOI of 50 for $24 \mathrm{~h}$ at $37^{\circ} \mathrm{C}$. Optimal knockdown and inhibition of autophagy was observed 5 days after transduction, which was the time point used for the subsequent experiments. JS1 cells were transfected with RFP-GFP-LC3B viral particles using a Premo Autophagy Tandem Sensor RFP-GFP-LC3B kit (Invitrogen; Thermo Fisher Scientific, Inc.) with an MOI of 30 for $24 \mathrm{~h}$ at $37^{\circ} \mathrm{C}$, and subsequently treated with $10 \mathrm{ng} / \mathrm{ml}$ TGF- $\beta 1$ alone or in combination with $50 \mu \mathrm{M}$ CQ for $24 \mathrm{~h}$. Treated cells were fixed with $4 \%$ paraformaldehyde for $30 \mathrm{~min}$ at room temperature and autophagic flux was observed using a confocal microscope (FV10C-PSU; Olympus Corporation).

Western blotting. Lysates of the liver or HSCs were prepared for electrophoresis as previously described (22). After resolving, protein concentration was measured using a bicinchoninic acid protein assay kit (cat. no. P0012; Beyotime Institute of Biotechnology). Proteins were separated by SDS-PAGE (5\% stacking gel, 10 or $15 \%$ separating gel; $30 \mu \mathrm{g}$ protein in $15 \mu \mathrm{l}$ loaded per lane) and subsequently transferred to a PVDF membrane. The membrane was blocked using blocking buffer (cat. no. 927-40000; LI-COR Biosciences) for $1 \mathrm{~h}$ at room temperature and incubated with primary antibody overnight at $4^{\circ} \mathrm{C}$. Subsequently, the membrane was incubated with a fluorescently tagged secondary antibody in the dark at room temperature for $45 \mathrm{~min}$ and read at a wavelength of $800 \mathrm{~nm}$ (780 nm excitation, $820 \mathrm{~nm}$ detection) or $700 \mathrm{~nm}$ (680 nm excitation, $720 \mathrm{~nm}$ detection) with an Odyssey Infrared Imaging system (Odyssey; LI-COR Biosciences) according to the manufacturer's instructions. ImageJ 6.0 (National Institutes of Health) was used for quantification. The antibodies used were as follows: Rabbit anti- $\alpha$-SMA (cat. no. 1184-1; Epitomics; Abcam), rabbit anti-collagen type I (Col.I; cat. no. ab292; Abcam), rabbit anti-Atg7 (cat. no. ab133528; Abcam), rabbit anti-LC3B (cat. no. L7543; Sigma-Aldrich; Merck KGaA), rabbit anti-p62 (cat. no. 5114; Cell Signaling Technology, Inc.), rabbit anti-cleaved-caspase 3 (cat. no. 9664; Cell Signaling Technology, Inc.), rabbit anti-Beclin-1 (cat. no. 3495; Cell Signaling Technology, Inc.), rabbit anti-JNK (cat. no. 9258; Cell Signaling Technology, Inc.), rabbit anti-phosphorylated (p)-JNK (cat. no. 4671; Cell Signaling Technology, Inc.), rabbit anti-ERK (cat. no. 4695; Cell Signaling Technology, Inc.), rabbit anti-p-ERK (cat. no. 4370; Cell Signaling Technology, Inc.), rabbit anti-p38 MAPK (cat. no. 8690; Cell Signaling Technology, Inc.), rabbit anti-p-p38 MAPK (cat. no. 4511; Cell Signaling Technology, Inc.), all at 1:500 dilution and mouse anti-GAPDH (cat. no. KC-5G4; 1:10,000; KangChen BioTech Co., Ltd.). The secondary antibodies used were as follows: IRDye 680RD goat anti-rabbit (cat. no. 926-68071; LI-COR Biosciences) and IRDye 800CW donkey anti-mouse (cat.no. 926-32212; LI-COR Biosciences), all 1:10,000 dilution.

Reverse transcription-quantitative (RT-q) PCR. RT-qPCR was performed as previously described to determine the gene expression levels in the cultured cells (23). Total RNA was extracted from the cells using a Nucleic Acid Purification kit (cat. no. NPK-201; Toyobo Life Science), and cDNA was synthesized using a RevertAid First Strand cDNA Synthesis kit (cat. no. K1622; Thermo Fisher Scientific, Inc.) according to the manufacturer's instructions. Total cDNA was mixed with PCR master mix (cat. no. DRR041A; Takara Bio, Inc.), and pre-designed primers. The following primer pairs (synthesized by Sangon Biotech co., Ltd.) were used for the qPCR: $\alpha$-SMA forward, 5'-ACTACTGCCGAGCGTGAGATT G-3' and reverse, 5'-CGTCAGGCAGTTCGTAGCTCTT-3'; Col.I, forward, 5'-GGACCTCCGGCTCCTGCTCCTC-3' and reverse, 5'-GCATTGCACGTCATCGCACAC-3'; beclin 1 forward, 5'-CTTACCACAGCCCAGGCGAA-3' and reverse, 5'-AGATGCCTCCCCGATCAGAG-3'; Atg5 forward, 5'-TAT CAGACCACGACGGAGCG-3' and reverse, 5'-CTGGCT CCTCTTCTCTCCATCTTC-3'; Bcl-2 forward, 5'-TGTGGA GAGCGTCAACAGGG-3' and reverse, 5'-AGACAGCCA GGAGAAATCAAACAGA-3'; p21 forward, 5'-ATGTCCAAT CCTGGTGATGTCC-3' and reverse, 5'-AAGTCAAAGTTC CACCGTTCTCG-3'; p53 forward, 5'-CGCCGACCTATC CTTACCATCAT-3' and reverse, 5'-CTCCCAGGGCAGGCA CAAAC-3' and GAPDH forward, 5'-AAGGTCATCCATGAC AACTTTGGC-3' and reverse, 5'-ACAGTCTTCTGGGTG GCAGTGAT-3'. GAPDH was used as the internal reference gene. The thermocycling conditions used for the qPCR were as follows: Initial denaturation for $1 \mathrm{~min}$ at $95^{\circ} \mathrm{C}$; followed by 40 cycles of $15 \mathrm{sec}$ at $95^{\circ} \mathrm{C}$ and $30 \mathrm{sec}$ at $60^{\circ} \mathrm{C}$. Amplification was performed on a ViiA7 system (Thermo Fisher Scientific, Inc.). Gene expression was normalized to that of GAPDH using the $2^{-\Delta \Delta \mathrm{Cq}}$ method (24).

Flow cytometry analysis of apoptosis. JS1 cells were incubated with TGF- $\beta 1(10 \mathrm{ng} / \mathrm{ml})$ for $12 \mathrm{~h}$ and pre-treated with or without $10 \mu \mathrm{M}$ SB203580 (cat. no. ab120162; Abcam) for $1 \mathrm{~h}$. In the absence or presence of the previously mentioned agents, JS1 cells were labeled with PE Annexin V and 7-amino-actinomycin using a PE Annexin V Apoptosis Detection kit according to the manufacturer's protocol (BD Biosciences) and analyzed using flow cytometry (DxFLEX; Beckman Coulter, Inc.). Flow cytometry data were analyzed using CytExpert software (version 2.0; Beckman Coulter, Inc.).

Statistical analysis. Data were collected in triplicate from at least three separate cell cultures. Results are expressed as the mean \pm SEM of three repeats. Differences amongst groups were compared using a one-way ANOVA followed by Tukey's post hoc test, or otherwise a t-test. SPSS 17.0 (SPSS, Inc.) was used to perform statistical analysis. $\mathrm{P}<0.05$ was considered to indicate a statistically significant difference.

\section{Results}

Autophagy is increased in liver tissues and HSCs following $\mathrm{CCL}_{4}$-induced injury. The expression of LC3BII and Atg7 was assessed using western blotting to determine the extent of autophagy in liver samples of mice with acute and chronic liver injury induced by $\mathrm{CCl}_{4}$. The results showed that LC3BII expression was significantly higher in both hepatic injury models compared with the control (Fig. 1A). The expression of Atg7, another autophagy-related protein, which promotes the conjugation of LC3-I to phosphatidylethanolamine to form 
A

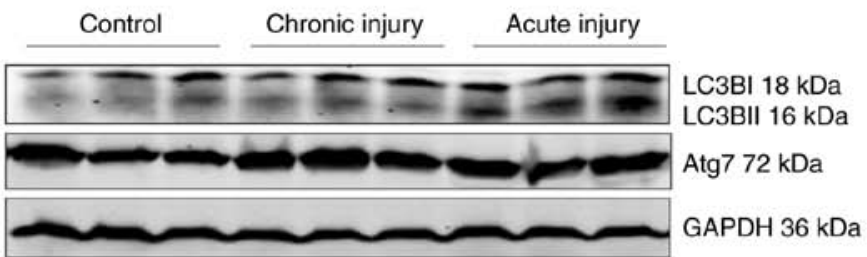

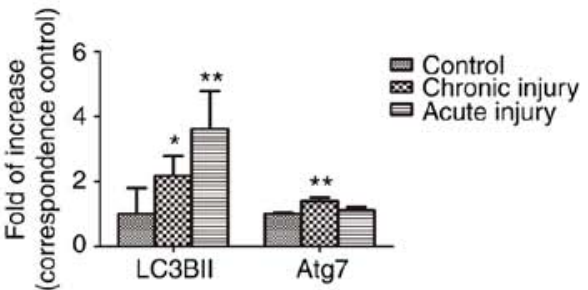

B

$\alpha$-SMA/Cy3
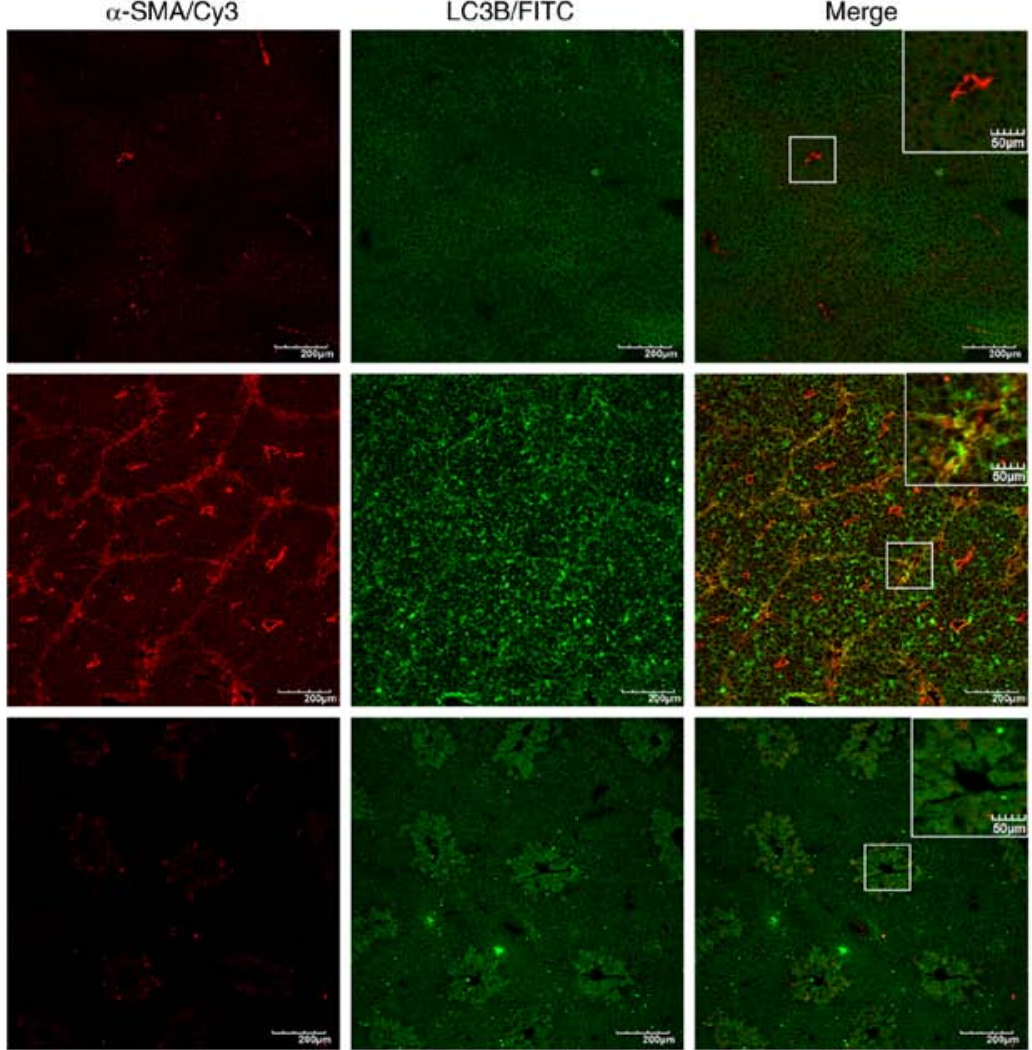

C

Control $\mathrm{CCl}_{4}$

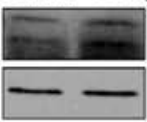

C3BI $18 \mathrm{kDa}$

CC3BII $16 \mathrm{kDa}$

GAPDH $36 \mathrm{kDa}$

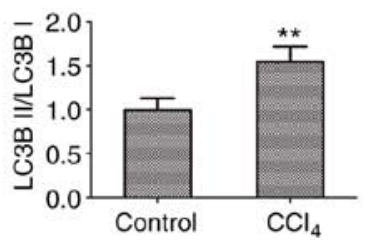

Figure 1. Autophagy is increased in liver tissues and HSCs following $\mathrm{CCL}_{4}$-induced injury. (A) Autophagy is upregulated in liver tissues following treatment with $\mathrm{CCl}_{4}$. LC3BI/II and Atg7 expression was significantly increased compared with the control. ${ }^{*} \mathrm{P}<0.05$ and ${ }^{* *} \mathrm{P}<0.01$ vs. control. (B) Confocal microscopy of co-immunostaining of $\alpha$-SMA (red) and LC3B (green) in mouse liver sections. Scale bars, 200 and $50 \mu \mathrm{m}$. (C) Western blotting showed that LC3BII is upregulated in primary $\mathrm{HSCs}$ isolated from mice with $\mathrm{CCl}_{4}$-induced acute liver injury. ${ }^{* *} \mathrm{P}<0.01$ vs. control. Protein ratios were used to quantify fold change relative to the control. Data are presented as the mean \pm the standard error of the mean of three independent repeats, and three animals were used per condition. $\mathrm{CCL}_{4}$, carbon tetrachloride; LC3B, microtubule-associated protein 1 light chain 3B; $\alpha$-SMA, $\alpha$-smooth muscle actin; HSC, hepatic stellate cell; Atg7, autophagy-related gene 7.

LC3-II, was significantly increased in the chronic injury group, and only slightly increased in the acute injury model (Fig. 1A).

Confocal microscopy was used to determine the relationship between HSCs and autophagy, and to monitor the co-localization of $\alpha$-SMA (a marker of HSC activation) and LC3B (a marker of autophagy). Autophagy and activation of HSC occurred simultaneously in fibrotic liver tissue. As shown in Fig. 1B, marked co-localization between $\alpha$-SMA and LC3B was observed in the chronic injury tissue. However, $\alpha$-SMA expression was only observed around the vessels, whereas LC3B expression was hardly observed, and there was no co-localization in the normal liver tissue. Primary mouse
HSCs were isolated from the acute injury liver tissue to show that autophagy was increased following activation of HSCs in vivo. The expression of LC3BII in HSCs from injured liver tissues was significantly higher compared with the control (Fig. 1C). These findings are consistent with those of previous reports $(13,14)$, showing that hepatic fibrosis is accompanied by autophagy.

TGF- $\beta 1$ simultaneously induces activation and autophagy in JS1 cells. One of the most characteristic features of HSC activation is the loss of lipid droplets (25). As shown in Fig. 2A, TGF- $\beta 1$ significantly promoted the loss of lipid 
droplets in primary HSCs. Consistent with previous studies, autophagy regulated hepatic metabolism $(7,8)$, and stimulated the loss of lipid droplets to provide energy for the activation of HSCs (12). Subsequently, whether there was an association between TGF- $\beta 1$-induced activation and autophagy in HSC was assessed.

JS1 cells were used to study TGF- $\beta 1$-induced fibrosis and autophagy. TGF- $\beta 1$ significantly increased the expression of the fibrosis markers $\alpha$-SMA and Col.I in these cells compared with controls (Fig. 2B and C). Autophagic bodies were clearly observed in JS1 cells treated with $10 \mathrm{ng} / \mathrm{ml}$ TGF- $\beta 1$ for $2 \mathrm{~h}$ through transmission electron microscopy. More autophagic bodies were observed when cells were co-treated with $10 \mathrm{ng} / \mathrm{ml}$ TGF- $\beta 1$ and $100 \mathrm{ng} / \mathrm{ml}$ rapamycin (Fig. 2D). Moreover, compared with controls, $10 \mathrm{ng} / \mathrm{ml}$ TGF- $\beta 1$ significantly induced the expression of LC3BII (Fig. 2E) and significantly upregulated the mRNA expression levels the of autophagy-related genes, Atg5 and Beclin-1 (Fig. 2F). These results also indicated that TGF- $\beta 1$ may induce autophagy in JS1 cells. LC3BII expression was significantly increased $12 \mathrm{~h}$ after treatment with TGF- $\beta 1$. Conversely, the expression of cleaved-caspase 3 was significantly inhibited at 12 and $24 \mathrm{~h}$ after treatment with TGF- $\beta 1$. These results suggested that treatment with TGF- $\beta 1$ protected JS1 against apoptosis. The results of PCR analysis are shown in Fig. 2F. The results showed that compared with controls, the mRNA expression levels of p21 and Bcl-2 (anti-apoptosis genes) were significantly upregulated, whereas the levels of p53 (pro-apoptotic gene) was downregulated. These results indicate a negative association between the induction of autophagy and suppression of apoptosis following treatment with TGF- $\beta 1$ in JS1 cells, which may be attributed to crosstalk between autophagy and apoptosis (26).

JS1 cells were transfected with a viral vector containing RFP-GFP-LC3B to confirm that treatment with TGF- $\beta 1$ increased the expression of LC3BII, rather than leading to its accumulation by blocking the turnover of LC3BII. The immunofluorescence data indicated a significant increase in punctate LC3BII staining in JS1 cells treated with TGF- $\beta 1$. Under physiological conditions, autophagic activity proceeded at a very low level, leading to yellow puncta being diffusely distributed in the cytoplasm. In addition, treatment with TGF- $\beta 1$ increased immunofluorescence staining of autophagosomes (yellow) and autolysosomes (red) compared with the control (Fig. 2G and $\mathrm{H}$ ).

Treatment with CQ inhibited autophagy by suppressing the fusion of autophagosomes and lysosomes, further confirming that TGF- $\beta 1$ induced autophagy. As shown in Fig. 2G, JS1 cells treated with CQ demonstrated only bright yellow fluorescent puncta. This was attributed to blockage of the maturation of autophagosomes into autolysosomes, thus the GFP signal could not be quenched by lysosomal fusion. The presence of yellow puncta was more prominent in the cytoplasm when co-treated with TGF- $\beta 1$ and CQ, suggesting that TGF- $\beta 1$ increased autophagosome synthesis. Another autophagy inhibitor, 3-MA, and the autophagy inducer rapamycin were used to further assess the presence of autophagy flux. These data demonstrated that compared with controls, pretreatment with 3-MA significantly inhibited TGF- $\beta 1$-induced LC3BII expression, whereas treatment with $\mathrm{CQ}$ and rapamycin significantly increased the expression of LC3BII in JS1 cells (Fig. 2I). Collectively, these data supported the notion that TGF- $\beta 1$ induces autophagy in JS1 cells.

Inhibition of autophagy attenuates the activation of JSI cells induced by $T G F-\beta 1$. It was hypothesized that autophagy was involved in TGF- $\beta 1$-induced activation of HSCs. Therefore, blocking autophagy may attenuate the activation of HSCs. The effects of JS1 cell stimulation by TGF- $\beta 1$ in the presence of autophagy inhibitors were assessed. The results suggested that treatment with 3-MA or CQ significantly inhibited TGF- $\beta 1$-induced activation of JS1 cells. As shown in Fig. 3A, 3 -MA or CQ inhibited TGF- $\beta 1$-induced proliferation. Moreover, CQ significantly inhibited TGF- $\beta 1$-induced expression (both at the mRNA and protein expression level) of $\alpha$-SMA and Col.I in JS1 cells (Fig. 3C and D). However, 3 -MA only suppressed the expression of $\alpha$-SMA mRNA and protein of Col.I (Fig. 3B and D). This may due to 3-MA not only blocking class III PI3K, but also class I PI3K.

As previously described (27), Atg7 is a protein-coding gene which promotes the conjugation of LC3-I to phosphatidylethanolamine to form LC3-II. shAtg7 lentiviral vector was used to interfere with the formation of the essential autophagy gene product, Atg7. The results suggested that JS1 cells infected with shAtg7 lentiviral vector significantly reduced the protein expression levels of Atg7. Following treatment with TGF- $\beta 1$, LC3BII and Col.I expression was significantly inhibited compared with the corresponding empty vector control (Fig. 3E). Therefore, inhibition of autophagy may reduce TGF- $\beta 1$-induced activation of JS1 cells, suggesting that TGF- $\beta 1$-induced autophagy might be required for fibrosis in HSCs.

TGF- $\beta 1$ induces autophagy via activation of ERK and JNK of the MAPK signaling pathway. The mechanism involved in autophagy was next investigated. The MAPK signaling pathway has been shown to be associated with cell proliferation, differentiation, migration, senescence, autophagy and apoptosis (28). In addition, previous studies have shown that TGF- $\beta 1$-induced activation of HSCs is associated with the MAPK signaling pathway $(22,29,30)$. The results of the present study showed that TGF- $\beta 1$ simultaneously induced autophagy and fibrosis in HSCs, and that inhibition of autophagy is associated with a concurrent reduction in TGF- $\beta 1$-induced fibrosis. Thus, it was hypothesized that the MAPK pathway (including the ERK, JNK, and p38 MAPK cascades) may be involved in TGF- $\beta 1$-induced autophagy.

The effects of JS1 cell stimulation using TGF- $\beta 1$ in the presence of the ERK inhibitor PD98059, p38 MAPK inhibitor SB203580 and JNK inhibitor SP600125 were assessed to investigate the role of the MAPK signaling pathways in TGF- $\beta 1$-induced autophagy. Subsequently, expression of Col.I, $\alpha$-SMA and autophagy markers were examined using western blotting or PCR. As shown in Fig. 4A, the ERK inhibitor PD98059 abrogated ERK phosphorylation in the presence of TGF- $\beta 1$ after 2 and $12 \mathrm{~h}$. To investigate this further, the effects of PD98059 on autophagy and fibrosis were determined. TGF- $\beta 1$ treatment resulted in a significant increase in the expression of the autophagy markers LC3BII, beclin- 1 and Atg5, and the fibrosis markers Col.I and $\alpha$-SMA. These 
A
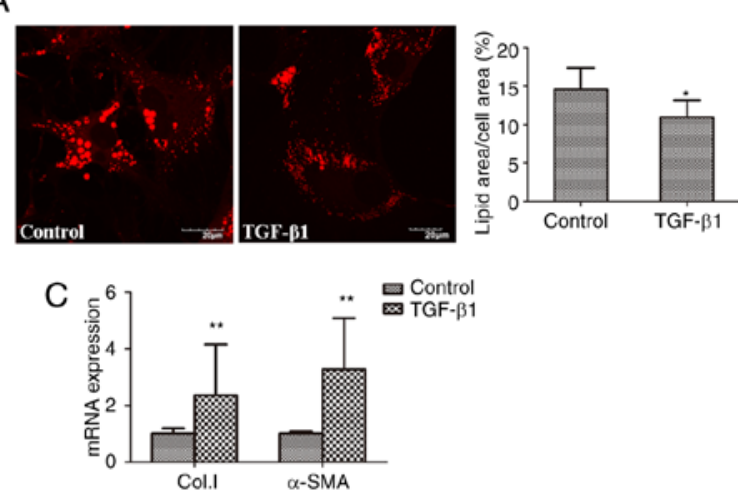

$\mathrm{E}$
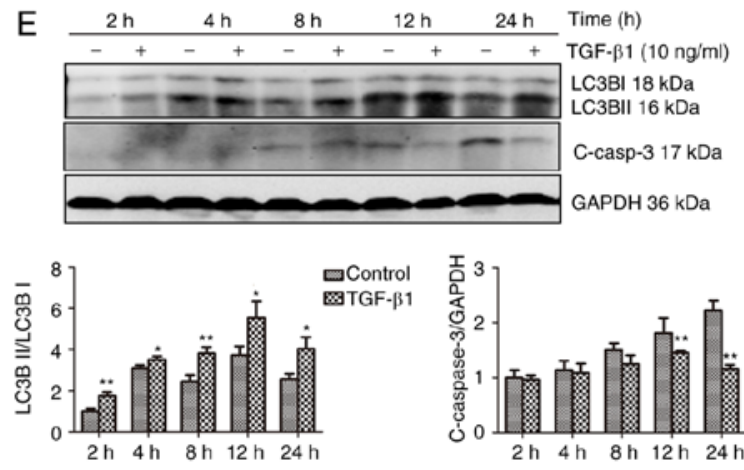

므나이

$\otimes$ TGF- $\beta 1$

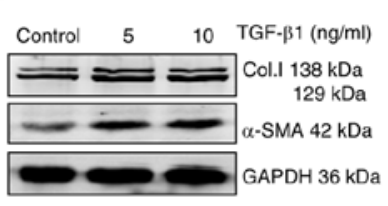

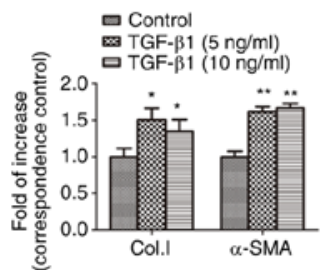

D

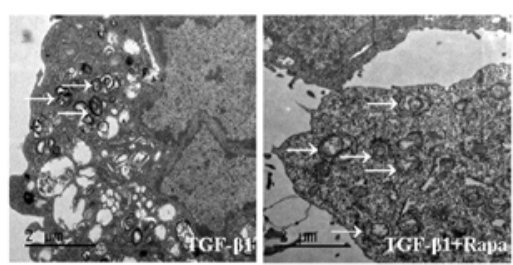

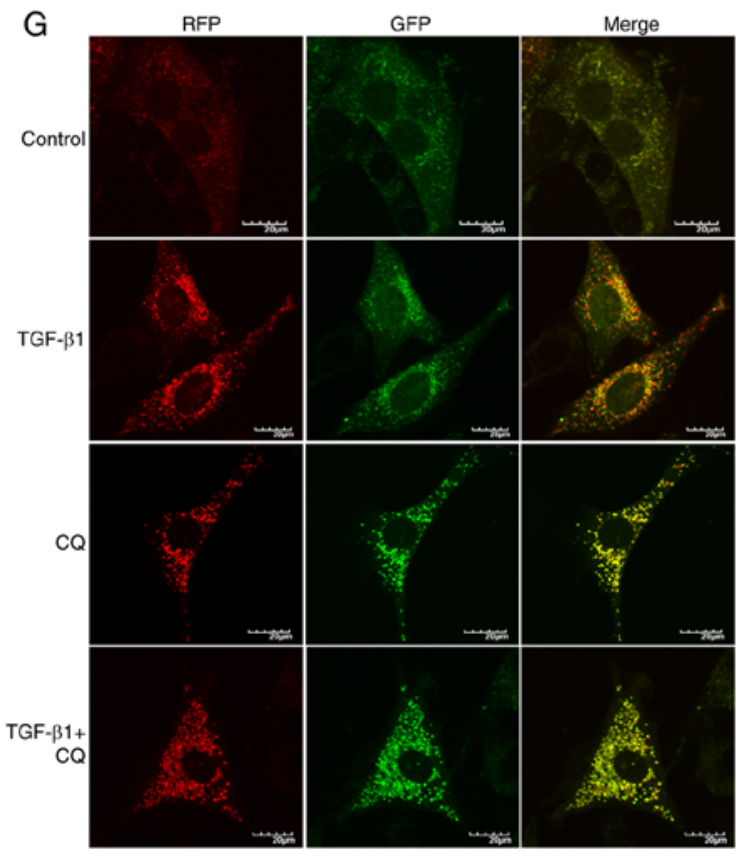
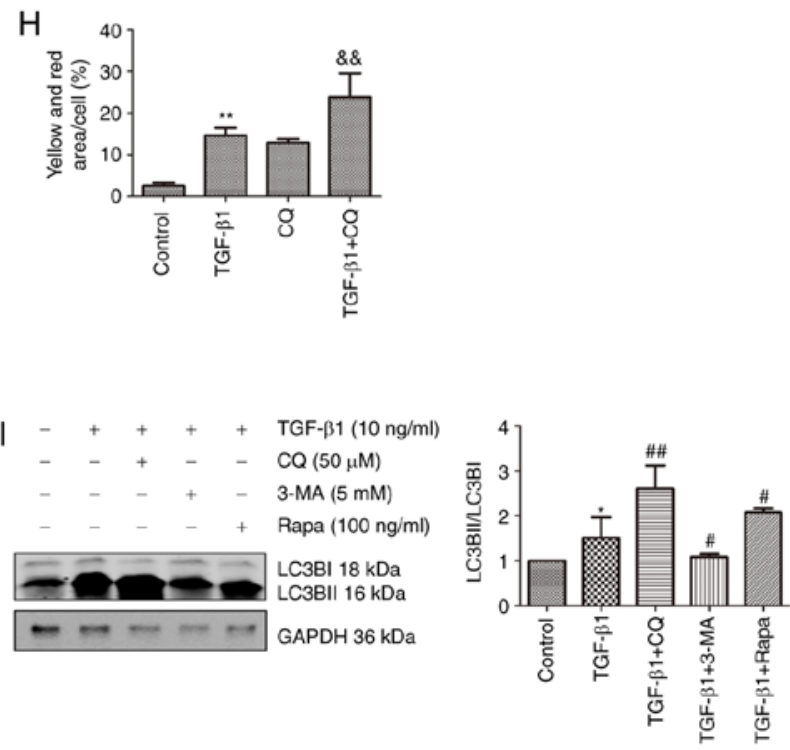

Figure 2. TGF- $\beta 1$ simultaneously induces activation and autophagy in JS1 cells. (A) On day 5 after isolation of primary HSCs, the cells were fixed, and lipid droplets were stained using BODIPY581/591 after treatment with $10 \mathrm{ng} / \mathrm{ml}$ TGF- $\beta 1$ for $24 \mathrm{~h}$. The quantity of droplets per cells was quantified. Scale bar, $20 \mu \mathrm{m}$. "P<0.05 vs. control. (B) JS1 cells were treated with TGF- $\beta 1$ (5 or $10 \mathrm{ng} / \mathrm{ml})$ for $24 \mathrm{~h}$. Western blotting was performed to assess the expression of fibrosis-associated markers $\alpha$-SMA and Col.I. (C) mRNA expression levels of $\alpha$-SMA and Col.I in JS1 cells were determined using reverse transcriptionquantitative PCR following treatment with $10 \mathrm{ng} / \mathrm{ml}$ TGF- $\beta 1$ for $24 \mathrm{~h}$. (D) JS1 cells were either treated with $10 \mathrm{ng} / \mathrm{ml}$ TGF- $\beta 1$ either alone or in combination with $100 \mathrm{ng} / \mathrm{ml}$ rapamycin for $2 \mathrm{~h}$. Cells were fixed and subsequently imaged using transmission electron microscopy. Autophagosomes (indicated by the white arrows) were clearly visible in the cytoplasm and were more abundant in cells treated with both TGF- $\beta 1$ and rapamycin. Scale bar, $2 \mu \mathrm{m}$. (E) Protein expression levels of LC3BII and cleaved-caspase-3 were detected by western blotting after incubation of JS1 cells with $10 \mathrm{ng} / \mathrm{ml} \mathrm{TGF-} \beta 1$ for $2,4,8,12 \mathrm{or} 24 \mathrm{~h}$. (F) mRNA expression levels of Beclin-1, Atg5, p21, Bcl-2 and p53 in JS1 cells incubated with $10 \mathrm{ng} / \mathrm{ml} \mathrm{TGF-} \beta 1$ for $24 \mathrm{~h}$. (G and H) JS1 cells were transfected with an RFP-GFP-LC3B virus vectors for $24 \mathrm{~h}$, and subsequently treated with $10 \mathrm{ng} / \mathrm{ml}$ TGF- $\beta 1$ alone or in combination with $50 \mu \mathrm{M}$ CQ for $24 \mathrm{~h}$. Cells were imaged using a confocal microscope. A total of 10 different fields (10 cells per field) were randomly selected and manually counted. The percentage of cells with yellow (colocalization of GFP and RFP) and red puncta (autophagosomes and lysosomes merged with GFP quenched) were compared with the control and treatment with CQ groups alone. TGF- $\beta 1$ significantly increased the number of autophagosomes and autolysosomes. Scale bar, $20 \mu \mathrm{m}$. ${ }^{* *} \mathrm{P}<0.01 \mathrm{vs}$. control; ${ }^{\&} \mathrm{P}<0.01$ vs. CQ. (I) JS1 cells were incubated with $10 \mathrm{ng} / \mathrm{ml} \mathrm{TGF}-\beta 1$ for $12 \mathrm{~h}$, and subsequently pretreated with $5 \mathrm{mM} 3-\mathrm{MA}, 50 \mu \mathrm{m} \mathrm{CQ} \mathrm{for} 2 \mathrm{~h}$, or $100 \mathrm{ng} / \mathrm{ml}$ rapamycin for $2 \mathrm{~h}$. LC3BII was detected using western blotting. Protein ratios were used to quantify fold change relative to the control. The mRNA expression levels were expressed as the fold-change relative to control. ${ }^{~} \mathrm{P}<0.05$ and ${ }^{* *} \mathrm{P}<0.01$ vs. control; ${ }^{*} \mathrm{P}<0.05$ and ${ }^{\# \#} \mathrm{P}<0.01$ vs. TGF- $\beta 1$. Data are presented as the mean \pm the standard error of the mean. LC3B, microtubule-associated protein 1 light chain 3B; $\alpha$-SMA, $\alpha$-smooth muscle actin; HSC, hepatic stellate cell; Col.I, collagen type I; TGF- $\beta 1$, transforming growth factor- $\beta 1$; CQ, chloroquine; 3-MA, 3-methyladenine; C-Casp3, cleaved caspase-3; Rapa, rapamycin. 
A

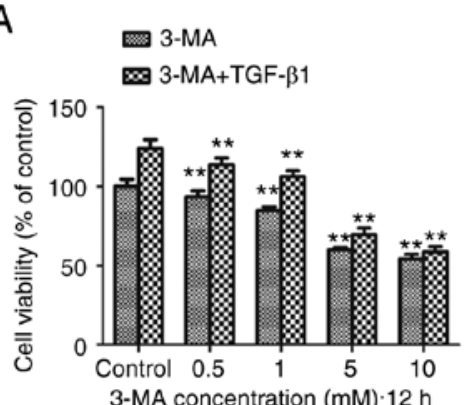

3-MA concentration $(\mathrm{mM}) \cdot 12 \mathrm{~h}$

대 $\mathrm{CQ}$

$\bowtie \mathrm{CQ}+\mathrm{TGF}-\beta 1$

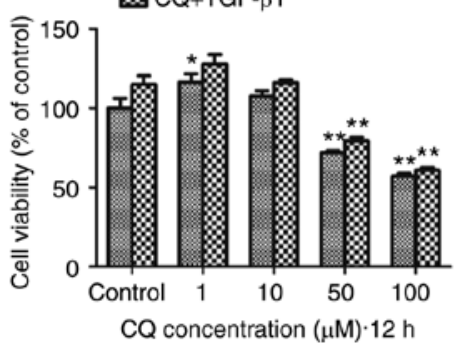

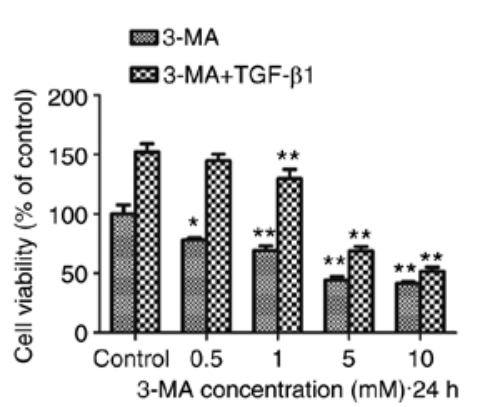

$\square \mathrm{CQ}$

$\bowtie C Q+T G F-\beta 1$

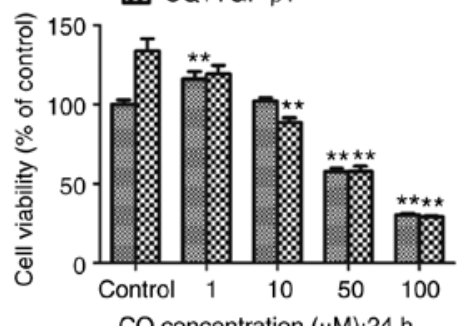

B $\quad$ 㫼ontrol

两TGF- $\beta 1$

曰

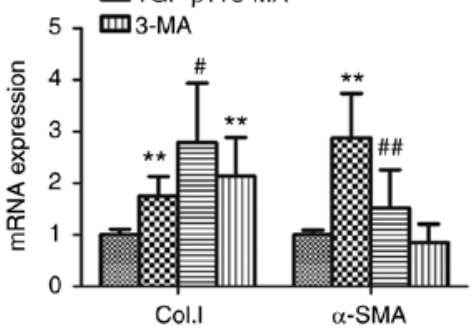

C $\quad$ Control

两 TGF- $\beta 1$

曰TGF- $\beta 1+3-\mathrm{CO}$

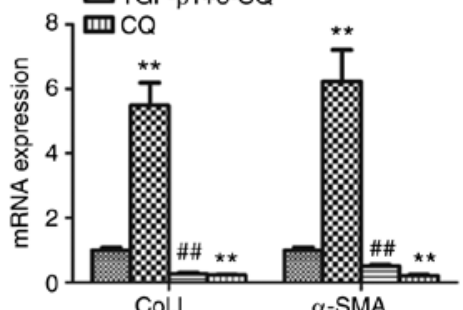

D
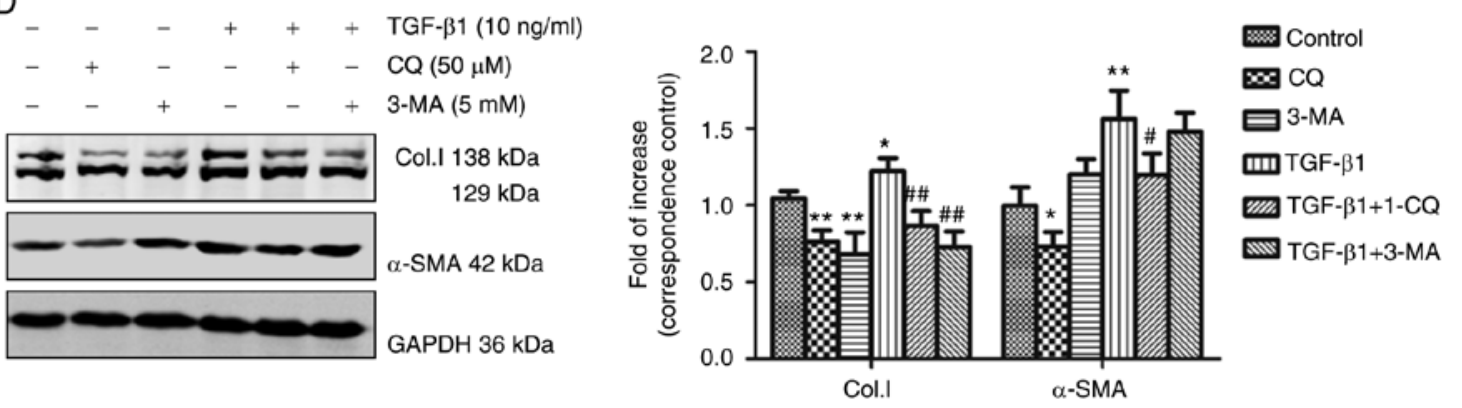

E
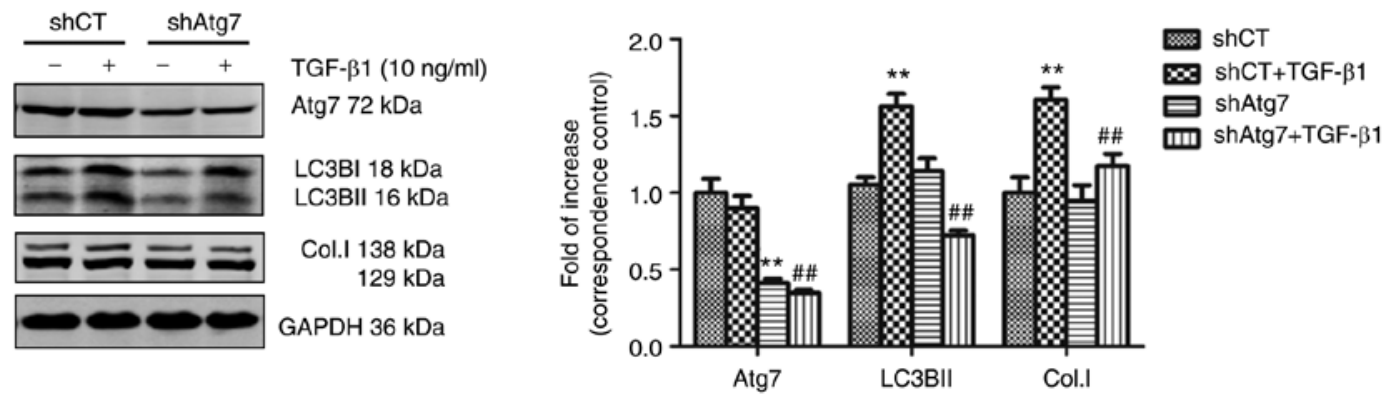

Figure 3. Inhibition of autophagy either by treatment with pharmacological inhibitors or shAtg7 reduces TGF- $\beta 1$-induced activation of JS1 cells. (A) Cell viability was determined using an MTT assay. JS1 cells were incubated with 3 -MA $(0.5,1,5$ or $10 \mathrm{mM})$ or CQ (10, 50 or $100 \mu \mathrm{M}) \mathrm{with}$ or without $10 \mathrm{ng} / \mathrm{ml}$ TGF- $\beta 1$ for 12 or $24 \mathrm{~h}$. Absorbance values at each concentration were obtained by comparison with their respective controls. * $\mathrm{P}<0.05$ and ${ }^{* *} \mathrm{P}<0.01$ vs. corresponding control. JS1 cells were incubated with $10 \mathrm{ng} / \mathrm{ml}$ TGF- $\beta 1$ combined with (B) $50 \mu \mathrm{M}$ CQ or (C) $5 \mathrm{mM} 3-\mathrm{MA}$ for $24 \mathrm{~h}$. The mRNA expression levels of $\alpha$-SMA and Col.I were detected through reverse transcription-quantitative PCR and expressed as the fold change relative to the control. ${ }^{* *} \mathrm{P}<0.01$ vs. control; ${ }^{\#} \mathrm{P}<0.05$ and ${ }^{\# \#} \mathrm{P}<0.01$ vs. TGF- $\beta 1$. (D) JS1 cells were incubated with $10 \mathrm{ng} / \mathrm{ml}$ TGF- $\beta 1$ in combination with $50 \mu \mathrm{M}$ CQ or $5 \mathrm{mM} 3-\mathrm{MA}$ for $12 \mathrm{~h}$. The protein expression levels of $\alpha$-SMA and Col.I were detected through western blotting. Protein ratios were used to quantify fold change relative to control. ${ }^{*} \mathrm{P}<0.05$ and ${ }^{* *} \mathrm{P}<0.01$ vs. control; ${ }^{\#} \mathrm{P}<0.05$ and ${ }^{\# \#} \mathrm{P}<0.01$ vs. TGF- $\beta 1$. (E) JS1 cells were transduced with shAtg7 lentiviral vector for 5 days, and subsequently incubated with $10 \mathrm{ng} / \mathrm{ml}$ TGF- $\beta 1$ for $24 \mathrm{~h}$. Western blotting was used to detect the expression of Atg7, LC3B and Col.I in JS1 cells. Protein ratios were used to quantify fold change relative to control. ${ }^{* *} \mathrm{P}<0.01$ vs. shCT; ${ }^{\# \#} \mathrm{P}<0.01 \mathrm{vs}$. shCT $+\mathrm{TGF}-\beta 1$. Data are presented as the mean \pm the standard error of the mean. LC3B, microtubule-associated protein 1 light chain 3B; $\alpha$-SMA, $\alpha$-smooth muscle actin; Col.I, collagen type I; TGF- $\beta 1$, transforming growth factor- $\beta 1$; CQ, chloroquine; 3-MA, 3-methyladenine; shRNA, small hairpin RNA; CT, control.

effects were partially reversed by treatment with PD98059 (Fig. 4B and C). As shown in Fig. 4D and E, the JNK inhibitor SP600125 reversed JNK phosphorylation and significantly decreased the expression of autophagy and fibrosis markers in the presence of TGF- $\beta 1$. In summary, TGF- $\beta 1$-induced autophagy and fibrosis were reduced following inhibition of the ERK and JNK signaling pathways.

Treatment with the p38 MAPK inhibitor SB203580 resulted in phosphorylation of p38 MAPK (Fig. 4F) and significantly increased the expression of LC3BII in JS1 cells (Fig. 4G). 
A

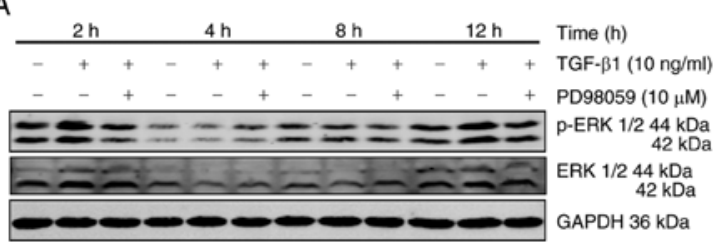

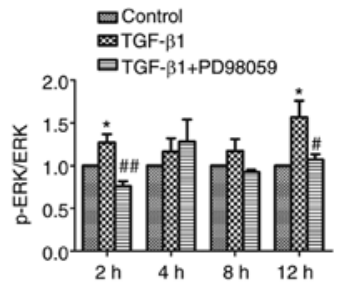

C $\square$ Control

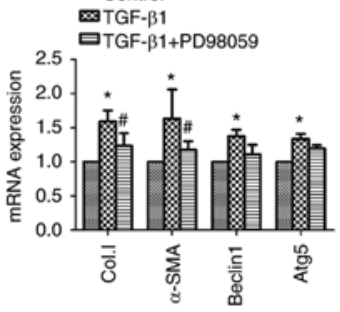

E $\square$ Control

ॠGF- $\beta 1$

曰TGF- $\beta 1+S P 600125$

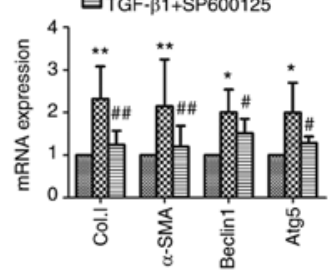

口 Control

$\triangle$ TGF- $\beta$

口 TGF- $\beta 1+S B 203580$

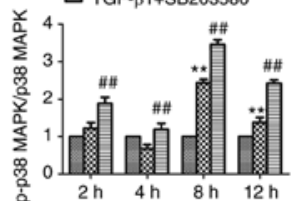

$\mathrm{H} \square$ Control

TGF- $\beta 1$
TGF- $\beta 1+$ SB203580

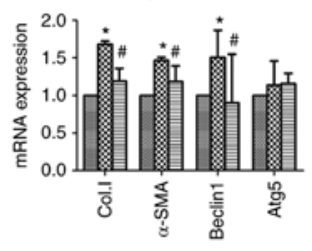

I
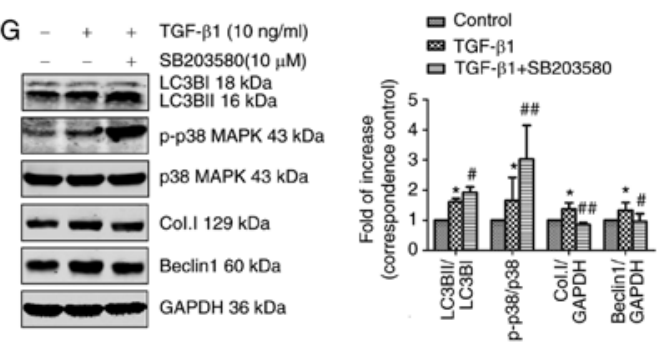

TGF. $\beta 1(10 \mathrm{ng} / \mathrm{ml})$ SB203580 $(10 \mu \mathrm{M})$ p-p38 MAPK 43 kDa p38 MAPK $43 \mathrm{kDa}$ GAPDH $36 \mathrm{kDa}$
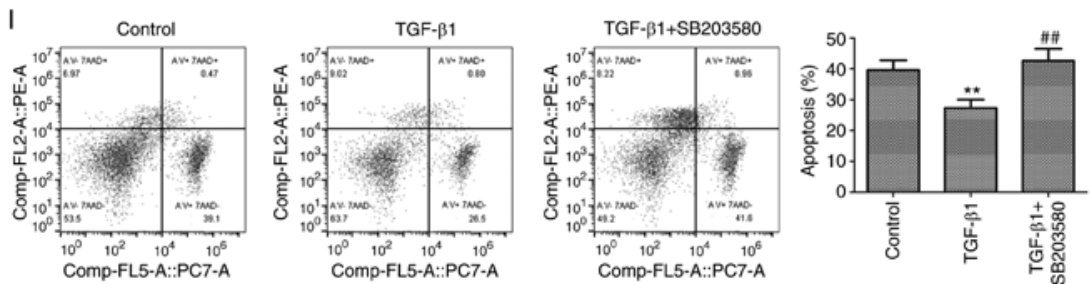

Figure 4. TGF- $\beta 1$ induces autophagy via activation of the ERK and JNK signaling pathways. (A) JS1 cells were pretreated with or without $10 \mu \mathrm{M}$ PD98059 for $1 \mathrm{~h}$ and incubated with $10 \mathrm{ng} / \mathrm{ml}$ TGF- $\beta 1$ for 2, 4,8 and $12 \mathrm{~h}$. The levels of p-ERK and ERK were detected through western blotting. JS1 cells were pretreated with or without $10 \mu \mathrm{M}$ PD 98059 for $1 \mathrm{~h}$ and incubated with $10 \mu \mathrm{M}$ TGF- $\beta 1$ for $12 \mathrm{~h}$. (B) Protein expression levels of LC3BII, p-ERK, ERK, Col.I and Beclin-1 were detected through western blotting. (C) mRNA expression of Col.I, $\alpha$-SMA, Beclin-1 and Atg5 were detected using RT-qPCR. JS1 cells were pretreated with or without $10 \mu$ M SP600125 for $1 \mathrm{~h}$ and incubated with $10 \mathrm{ng} / \mathrm{ml}$ TGF- $\beta 1$ for $12 \mathrm{~h}$. (D) The levels of LC3BII, JNK, p-JNK, Col.I and Beclin-1 were detected using western blotting. (E) The mRNA expression levels of Col.I, $\alpha$-SMA, Beclin-1 and Atg5 were detected using RT-qPCR. (F) JS1 cells were pretreated with or without $10 \mu$ M SB203580 for $1 \mathrm{~h}$ and incubated with $10 \mathrm{ng} / \mathrm{ml}$ TGF- $\beta 1$ for 2, 4,8 and $12 \mathrm{~h}$. The levels of p-p38 MAPK and p38 MAPK were detected through western blotting. JS1 cells were pretreated with or without $10 \mu \mathrm{M} \mathrm{SB} 203580$ for $1 \mathrm{~h}$ and incubated with $10 \mathrm{ng} / \mathrm{ml}$ TGF- $\beta 1$ for $12 \mathrm{~h}$. (G) The protein expression levels of LC3BII, p-p38 MAPK, p38 MAPK, Col.I and Beclin-1 were detected through western blotting. (H) The mRNA expression levels of Col.I, $\alpha$-SMA, Beclin-1 and Atg5 were detected using RT-qPCR. (I) The proportion of apoptotic cells was assessed by flow cytometry using PE Annexin V and 7-AAD staining. Protein ratios were used to quantify fold-change relative to the control. The mRNA expression levels were expressed as the fold change relative to the control. ${ }^{*} \mathrm{P}<0.05$ and ${ }^{* *} \mathrm{P}<0.01$ vs. control; ${ }^{\#} \mathrm{P}<0.05$ and ${ }^{\# \#} \mathrm{P}<0.01$ vs. TGF- $\beta 1$. Data are presented as the mean \pm the standard error of the mean. TGF- $\beta 1$, transforming growth factor $-\beta 1 ;$ p phosphorylated; LC $3 \mathrm{~B}$, microtubule-associated protein 1 light chain 3B; RT-qPCR, reverse transcription-quantitative PCR; $\alpha$-SMA, $\alpha$-smooth muscle actin; Col.I, collagen type I; 7AAD, 7-actinomycin D. 
However, the expression of fibrosis markers and Beclin-1 induced by TGF- $\beta 1$ was significantly decreased following SB203580 treatment (Fig. 4G and H). Furthermore, whether the $\mathrm{p} 38$ MAPK signaling pathway regulated apoptosis rather than autophagy to participate in TGF- $\beta 1$-induced activation of HSCs was assessed. The rate of apoptosis was assessed using flow cytometry (Fig. 4I). Treatment with TGF- $\beta 1$ resulted in a significant decrease in apoptosis, which was reversed through pretreatment with SB203580. This finding supported the hypothesis that the p38 MAPK signaling pathway regulated TGF- $\beta 1$-induced activation of JS1 cells to inhibit apoptosis. In conclusion, these findings supported the notion that, unlike the p38 MAPK signaling cascade, ERK and JNK may be responsible for TGF- $\beta 1$-induced autophagy.

\section{Discussion}

In the present study, it was shown that TGF- $\beta 1$ simultaneously induced autophagy and fibrosis in a mouse HSC line. Moreover, inhibition of autophagy, either through the use of pharmacological inhibitors (CQ and 3-MA) or shAtg7, reduced TGF- $\beta 1$-induced fibrosis. These results showed that TGF- $\beta 1$ was able to induce autophagy in HSCs, thereby further showing that TGF- $\beta 1$-induced the activation of HSCs, and this mechanism was shown to be associated with the ERK and JNK signaling pathway.

Autophagy is a cellular pathway through which proteins and organelles are delivered to lysosomes for degradation, allowing for turnover of cell components and providing energy and macromolecular precursors (31). Basal level autophagy occurs in all types of cells; however, uncontrolled autophagy leads to programmed cell death (4). This duality of outcomes also manifests in the treatment of liver fibrosis. For example, oroxylin A (32) and caffeic acid phenethyl ester (33) attenuated liver fibrosis via activation of the autophagy pathway, whereas trolline (34) and quercetin (35) ameliorated liver fibrosis by suppressing autophagy.

The complex function of autophagy in promoting or preventing liver fibrosis may be dependent on different cells and different stages of the disease. Hernández-Gea et al (12) reported that autophagy stimulated the loss of lipid droplets, which provides cellular energy to promote survival and activation of HSCs. Lodder et al (36) found that atg $5^{-1}$ mice were more susceptible to liver fibrosis, as shown by enhanced matrix and fibrogenic cell accumulation. Hepatic myofibroblasts exposed to the conditioned medium of macrophages from atg $5^{-/}$mice showed increased profibrogenic gene expression. However, Hong et al (37) showed that activation of HSCs was inhibited in ATG2A-deficient LX2 cells. Ruart et al (38) recently suggested that the selective potentiation of autophagy in liver sinusoidal endothelial cells during the early stages of liver disease may be an attractive approach to modify the disease course and prevent the progression of fibrosis.

TGF- $\beta 1$ is a key regulator of different cellular processes and regulates both autophagy and fibrosis in numerous types of tissues. The effect of TGF- $\beta 1$ on autophagy has been previously reported in several fibrotic diseases, and its role may differ between various tissues or cells $(19,39-43)$. A number of studies have shown that TGF- $\beta 1$ induces autophagy. In cardiac fibrosis, TGF- $\beta 1$ increased autophagic activation and promoted fibrosis in primary human atrial myofibroblasts (19).
Moreover, in renal fibrosis, TGF- $\beta 1$ induced autophagy and protected glomerular mesangial cells via activation of the Akt pathway $(42,43)$. However, other studies reported contrasting results. In pulmonary fibrosis, autophagy was inhibited by TGF- $\beta 1$ in human lung fibroblast cells, and the expression of $\alpha$-SMA and fibronectin was enhanced $(39,40)$.

The results of the present study showed that the effect induced by TGF- $\beta 1$ was attenuated following inhibition of autophagy through treatment with pharmacological inhibitors (CQ and 3-MA) or shAtg7. CQ inhibits autophagy by suppressing the fusion of autophagosomes and lysosomes (44). Therefore, although the progression of autophagy was inhibited, autophagosome accumulation still occurred. 3-MA is an inhibitor of PI3K and has been widely used as an inhibitor of autophagy, based on its inhibitory effect on class III PI3K, which is essential for the induction of autophagy (45). However, 3-MA also blocks class I PI3K, which exhibits the opposite effect to that of class III PI3K (14). This may explain the upregulation of Col.I mRNA expression levels in JS1 cells incubated with 3-MA (5 mM) for $24 \mathrm{~h}$. A similar result was reported in mouse embryonic fibroblasts and primary HSCs (45). Finally, the results of the present study revealed that TGF- $\beta 1$ induced autophagy in HSCs, and autophagy is involved in TGF- $\beta 1$-induced activation of HSCs. Although these results are consistent with a previous study (26), contrasting results have also been reported. Thomes et al (46) found that exposure of primary rat HSCs to TGF- $\beta(5 \mathrm{ng} / \mathrm{ml})$ increased the levels of fibrogenic markers, but simultaneously decreased the rate of synthesis of autophagosomes. These conflicting results may suggest that the role of TGF- $\beta$ in autophagy is related to the level and duration of its activation.

The mechanism involved in the processes assessed were also determined. The MAPK signal transduction pathways are amongst the most widespread mechanisms involved in the regulation of eukaryotic cells (47). As shown previously, MAPKs can be activated by TGF- $\beta 1$ and regulate autophagy (48-52). In the present study, the role of the most extensively studied MAPK pathways (ERK, p38 and JNK) in TGF- $\beta 1$-induced autophagy were assessed. The ERK inhibitor, PD98059, and JNK inhibitor, SP600125, were able to attenuate TGF- $\beta 1$-induced autophagy and fibrosis in JS1 cells. Although the p38 MAPK inhibitor SB203580 decreased the activation of JS1 cells, an opposing effect on the autophagy pathway was observed. SB203580 resulted in phosphorylation of p38 MAPK and the induction of autophagy. Further investigation showed that activation of p38 MAPK may exert a protective effect, preventing apoptosis and cell death. According to these results, TGF- $\beta 1$ may induce autophagy through the activation of the ERK and JNK pathways and inhibit apoptosis via the p38 MAPK pathway in HSCs.

MAPK pathways, in particular p38 MAPK, serve dual roles in autophagy, and the role exhibited may depend upon the nature of the stimulus, and the level and duration of MAPK pathway activation. Webber (51), Webber and Tooze (52) reported that $\mathrm{p} 38 \alpha$ MAPK negatively regulates the levels of autophagy, and activation of $\mathrm{p} 38$ may exhibit a protective role against autophagy. In contrast, inhibition of p38 with SB203580 results in an induction of autophagy, and prolonged blockade leads to cell death with autophagic features. Moreover, activation of JNK contributes to autophagy and cell death. These findings are in agreement with the results of the present study. 
In conclusion, the present study showed that autophagy is involved in TGF- $\beta 1$-induced activation of HSCs. Furthermore, TGF- $\beta 1$ may partly induce autophagy to promote HSC activation via the ERK and JNK pathways. These results provide a novel framework for understanding the mechanism of TGF- $\beta 1$ and its involvement in the activation of HSCs. Additionally, the present study highlighted autophagy as a putative novel therapeutic target for the attenuation of fibrosis. However, crosstalk occurs between the ERK, JNK and p38 MAPK pathways, as well as autophagy and apoptosis. Thus, further research is warranted to investigate the molecular mechanisms of MAPK signaling, and its involvement in the regulation of autophagy.

\section{Acknowledgements}

We would like to thank Professor Scott L. Friedman (Icahn School of Medicine at Mount Sinai, USA) for providing the mouse immortalized HSC cell line, JS1. We would like to thank Professor Mark J. Czaja (Albert Einstein College of Medicine, USA) for providing shAtg7 expression plasmids.

\section{Funding}

The present study was supported by the General Program of the National Natural Science Foundation of China (grant no. 81373859$)$.

\section{Availability of data and materials}

The datasets used and/or analyzed during the current study are available from the corresponding author on reasonable request.

\section{Authors' contributions}

LX conceived and designed the study, contributed reagents and materials. JZ and NJ performed research and analyzed data. JZ wrote the manuscript. JP analyzed and interpreted the data and revised the manuscript. All authors read and approved the final manuscript.

\section{Ethics approval and consent to participate}

The experimental protocols used in the present study were approved by the Shuguang Hospital Affiliated to Shanghai University of Traditional Chinese Medicine Animal Care and Ethics committee.

\section{Patient consent for publication}

Not applicable.

\section{Competing interests}

The authors declare that they have no competing interests.

\section{References}

1. Lee UE and Friedman SL: Mechanisms of hepatic fibrogenesis. Best Pract Res Clin Gastroenterol 25: 195-206, 2011.

2. Tsuchida T and Friedman SL: Mechanisms of hepatic stellate cell activation. Nat Rev Gastroenterol Hepatol 14: 397-411, 2017.
3. Higashi T, Friedman SL and Hoshida Y: Hepatic stellate cells as key target in liver fibrosis. Adv Drug Deliv Rev 121: 27-42, 2017.

4. Mizushima N, Levine B, Cuervo AM and Klionsky DJ: Autophagy fights disease through cellular self-digestion. Nature 451: 1069-1075, 2008.

5. Tseng YJ, Dong L, Liu YF, Xu N, Ma W, Weng SQ, Janssen HLA and Wu SD: Role of autophagy in chronic liver inflammation and fibrosis. Curr Protein Pept Sci 20: 817-822, 2019.

6. Chao X and Ding WX: Role and mechanisms of autophagy in alcohol-induced liver injury. Adv Pharmacol 85: 109-131, 2019.

7. Cingolani F and Czaja MJ: Regulation and functions of autophagic lipolysis. Trends Endocrinol Metab 27: 696-705, 2016.

8. Carmona-Gutierrez D, Zimmermann A and Madeo F: A molecular mechanism for lipophagy regulation in the liver. Hepatology 61: 1781-1783, 2015.

9. Mao YQ and Fan XM: Autophagy: A new therapeutic target for liver fibrosis. World J Hepatol 7: 1982-1986, 2015.

10. Song Y, Zhao Y, Wang F, Tao L, Xiao J and Yang C: Autophagy in hepatic fibrosis. Biomed Res Int 2014: 436242, 2014.

11. Thoen LF, Guimarães EL, Dollé L, Mannaerts I, Najimi M, Sokal E and van Grunsven LA: A role for autophagy during hepatic stellate cell activation. J Hepatol 55: 1353-1360, 2011.

12. Hernández-Gea V, Ghiassi-Nejad Z, Rozenfeld R, Gordon R, Fiel MI, Yue Z, Czaja MJ and Friedman SL: Autophagy releases lipid that promotes fibrogenesis by activated hepatic stellate cells in mice and in human tissues. Gastroenterology 142: 938-946, 2012.

13. He W, Wang B, Yang J, Zhuang Y, Wang L, Huang X and Chen J: Chloroquine improved carbon tetrachloride-induced liver fibrosis through its inhibition of the activation of hepatic stellate cells: Role of autophagy. Biol Pharm Bull 37: 1505-1509, 2014.

14. Wang B, Yang H, Fan Y, Yang Y, Cao W, Jia Y, Cao Y, Sun K, Pang $\mathrm{Z}$ and Du H: 3-Methyladenine ameliorates liver fibrosis through autophagy regulated by the NF- $\mathrm{BB}$ signaling pathways on hepatic stellate cell. Oncotarget 8: 107603-107611, 2017.

15. Bridle KR, Popa C, Morgan ML, Sobbe AL, Clouston AD, Fletcher LM and Crawford DH: Rapamycin inhibits hepatic fibrosis in rats by attenuating multiple profibrogenic pathways. Liver Transpl 15: 1315-1324, 2009.

16. Wu N, Chen L, Yan D, Zhou M, Shao C, Lu Y, Yao Q, Sun H and Fu Y: Trehalose attenuates TGF- $\beta 1$-induced fibrosis of hSCFs by activating autophagy. Mol Cell Biochem 470: 175-188, 2020.

17. Nam SA, Kim WY, Kim JW, Park SH, Kim HL, Lee MS, Komatsu M, Ha H, Lim JH, Park CW, et al: Autophagy attenuates tubulointerstital fibrosis through regulating transforming growth factor- $\beta$ and NLRP3 inflammasome signaling pathway. Cell Death Dis 10: 78, 2019.

18. Ghavami S, Yeganeh B, Zeki AA, Shojaei S, Kenyon NJ, Ott S, Samali A, Patterson J, Alizadeh J, Alizadeh J, et al: Autophagy and the unfolded protein response promote profibrotic effects of TGF- $\beta 1$ in human lung fibroblasts. Am J Physiol Lung Cell Mol Physiol 314: L493-L504, 2018.

19. Ghavami S, Cunnington RH, Gupta S, Yeganeh B, Filomeno KL, Freed DH, Chen S, Klonisch T, Halayko AJ, Ambrose E, et al: Autophagy is a regulator of TGF- $\beta 1$-induced fibrogenesis in primary human atrial myofibroblasts. Cell Death Dis 6: e1696, 2015.

20. Wu J, Xing C, Zhang L, Mao H, Chen X, Liang M, Wang F, Ren H, Cui H, Jiang A, et al: Autophagy promotes fibrosis and apoptosis in the peritoneum during long-term peritoneal dialysis. J Cell Mol Med 22: 1190-1201, 2018.

21. Guo J, Loke J, Zheng F, Hong F, Yea S, Fukata M, Tarocchi M, Abar OT, Huang H, Sninsky JJ and Friedman SL: Functional linkage of cirrhosis-predictive single nucleotide polymorphisms of Toll-like receptor 4 to hepatic stellate cell responses. Hepatology 49: 960-968, 2009.

22. Lv Z, Song Y, Xue D, Zhang W, Cheng Y and Xu L: Effect of salvianolic-acid B on inhibiting MAPK signaling induced by transforming growth factor- $\beta 1$ in activated rat hepatic stellate cells. J Ethnopharmacol 132: 384-392, 2010.

23. Liu CH, Hu YY, Wang XL, Liu P and Xu LM: Effects of salvianolic acid-A on NIH/3T3 fibroblast proliferation, collagen synthesis and gene expression. World J Gastroenterol 6: 361-364, 2000.

24. Livak KJ and Schmittgen TD: Analysis of relative gene expression data using real-time quantitative PCR and the 2(-Delta Delta C(T)) method. Methods 25: 402-408, 2001.

25. BlanerWS, O'Byrne SM, Wongsiriroj N, Kluwe J,D'Ambrosio DM, Jiang H, Schwabe RF, Hillman EM, Piantedosi R and Libien J: Hepatic stellate cell lipid droplets: A specialized lipid droplet for retinoid storage. Biochim Biophys Acta 1791: 467-473, 2009. 
26. Fu MY, He YJ, Lv X, Liu ZH, Shen Y, Ye GR, Deng YM and Shu JC: Transforming growth factor- $\beta 1$ reduces apoptosis via autophagy activation in hepatic stellate cells. Mol Med Rep 10: $1282-1288,2014$

27. Mizushima N, Yoshimori T and Ohsumi Y: The role of Atg proteins in autophagosome formation. Annu Rev Cell Dev Biol 27: 107-132, 2011.

28. Sun Y, Liu WZ, Liu T, Feng X, Yang N and Zhou HF: Signaling pathway of MAPK/ERK in cell proliferation, differentiation, migration, senescence and apoptosis. J Recept Signal Transduct Res 35: 600-604, 2015.

29. Lv Z and $\mathrm{Xu}$ L: Salvianolic acid B inhibits ERK and p38 MAPK signaling in TGF- $\beta 1$-stimulated human hepatic stellate cell line (LX-2) via distinct pathways. Evid Based Complement Alternat Med 2012: 960128, 2012.

30. Zhang W, Ping J, Zhou Y, Chen G and Xu L: Salvianolic acid B inhibits activation of human primary hepatic stellate cells through downregulation of the myocyte enhancer factor 2 signaling pathway. Front Pharmacol 10: 322, 2019.

31. Levy JMM, Towers CG and Thorburn A: Targeting autophagy in cancer. Nat Rev Cancer 17: 528-542, 2017.

32. Chen W, Zhang Z, Yao Z, Wang L, Zhang F, Shao J, Chen A and Zheng S: Activation of autophagy is required for oroxylin A to alleviate carbon tetrachloride-induced liver fibrosis and hepatic stellate cell activation. Int Immunopharmacol 56: 148-155, 2018

33. Yang N, Dang S, Shi J, Wu F, Li M, Zhang X, Li Y, Jia X and Zhai S: Caffeic acid phenethyl ester attenuates liver fibrosis via inhibition of TGF- $\beta 1 /$ Smad3 pathway and induction of autophagy pathway. Biochem Biophys Res Commun 486: 22-28, 2017.

34. Bai F, Huang Q, Nie J, Lu S, Lu C, Zhu X, Wang Y, Zhuo L, $\mathrm{Lu} \mathrm{Z}$ and Lin $\mathrm{X}$ : Trolline ameliorates liver fibrosis by inhibiting the NF- $\kappa \mathrm{B}$ pathway, promoting HSC apoptosis and suppressing autophagy. Cell Physiol Biochem 44: 436-446, 2017.

35. Wu L, Zhang Q, Mo W, Feng J, Li S, Li J, Liu T, Xu S, Wang W, Lu X, et al: Quercetin prevents hepatic fibrosis by inhibiting hepatic stellate cell activation and reducing autophagy via the TGF-31/Smads and PI3K/Akt pathways. Sci Rep 7: 9289, 2017.

36. Lodder J, Denaës T, Chobert MN, Wan J, El-Benna J, Pawlotsky JM, Lotersztajn S and Teixeira-Clerc F: Macrophage autophagy protects against liver fibrosis in mice. Autophagy 11: 1280-1292, 2015.

37. Hong Y, Li S, Wang J and Li Y: Author correction: In vitro inhibition of hepatic stellate cell activation by the autophagy-related lipid droplet protein ATG2A. Sci Rep 8: 14569, 2018.

38. Ruart M,ChavarriaL,CampreciósG,Suárez-Herrera N,MontironiC, Guixé-Muntet S, Bosch J, Friedman SL, Garcia-Pagán JC and Hernández-Gea V: Impaired endothelial autophagy promotes liver fibrosis by aggravating the oxidative stress response during acute liver injury. J Hepatol 70: 458-469, 2019.
39. Patel AS, Lin L, Geyer A, Haspel JA, An CH, Cao J, Rosas IO and Morse D: Autophagy in idiopathic pulmonary fibrosis. PLoS One 7: e41394, 2012.

40. Araya J, Kojima J, Takasaka N, Ito S, Fujii S, Hara H, Yanagisawa $\mathrm{H}$, Kobayashi $\mathrm{K}$, Tsurushige C, Kawaishi M, et al: Insufficient autophagy in idiopathic pulmonary fibrosis. Am J Physiol Lung Cell Mol Physiol 304: L56-L69, 2013.

41. Ding Y, Kim JK, Kim SI, Na HJ, Jun SY, Lee SJ and Choi ME TGF- $\{$ beta $\} 1$ protects against mesangial cell apoptosis via induction of autophagy. J Biol Chem 285: 37909-37919, 2010.

42. Sureshbabu A, Muhsin SA and Choi ME: TGF- $\beta$ signaling in the kidney: Profibrotic and protective effects. Am J Physiol Renal Physiol 310: F596-F606, 2016.

43. Ding Y and Choi ME: Regulation of autophagy by TGF- $\beta$ : Emerging role in kidney fibrosis. Semin Nephrol 34: 62-71, 2014

44. Mizushima N, Yoshimori T and Levine B: Methods in mammalian autophagy research. Cell 140: 313-326, 2010.

45. Wu YT, Tan HL, Shui G, Bauvy C, Huang Q, Wenk MR, Ong CN, Codogno P and Shen HM: Dual role of 3-methyladenine in modulation of autophagy via different temporal patterns of inhibition on class I and III phosphoinositide 3-kinase. J Biol Chem 285: 10850-10861, 2010.

46. Thomes PG, Brandon-Warner E, Li T, Donohue TM Jr and Schrum LW: Rev-erb agonist and TGF- $\beta$ similarly affect autophagy but differentially regulate hepatic stellate cell fibrogenic phenotype. Int J Biochem Cell Biol 81: 137-147, 2016.

47. Krishna $M$ and Narang $H$ : The complexity of mitogen-activated protein kinases (MAPKs) made simple. Cell Mol Life Sci 65: 3525-3544, 2008

48. Zhou YY, Li Y, Jiang WQ and Zhou LF: MAPK/JNK signalling: A potential autophagy regulation pathway. Biosci Rep 35: e00199, 2015.

49. Cagnol S and Chambard JC: ERK and cell death: Mechanisms of ERK-induced cell death-apoptosis, autophagy and senescence. FEBS J 277: 2-21, 2010.

50. Xu XF, Liu F, Xin JQ, Fan JW, Wu N, Zhu LJ, Duan LF, Li YY and Zhang $\mathrm{H}$ : Respective roles of the mitogen-activated protein kinase (MAPK) family members in pancreatic stellate cell activation induced by transforming growth factor- $\beta 1$ (TGF- $\beta 1$ ). Biochem Biophys Res Commun 501: 365-373, 2018

51. Webber JL: Regulation of autophagy by p38alpha MAPK. Autophagy 6: 292-293, 2010.

52. Webber JL and Tooze SA: Coordinated regulation of autophagy by $\mathrm{p} 38$ alpha MAPK through mAtg9 and p38IP. EMBO J 29 27-40, 2010.

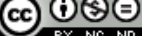

This work is licensed under a Creative Commons Attribution-NonCommercial-NoDerivatives 4.0 International (CC BY-NC-ND 4.0) License. 